\title{
Isolation and Characterization of a Clone of the spoVE Locus of Bacillus subtilis
}

\author{
By P. J. PIGGOT ${ }^{*} \dagger$, K.-F. CHAK ${ }^{1} \ddagger$ AND U. D. BUGAICHUK ${ }^{2}$ \\ 'Division of Microbiology, National Institute for Medical Research, The Ridgeway, Mill Hill, \\ London NW7 IAA, UK \\ ${ }^{2}$ Microbiology Unit, Department of Biochemistry, University of Oxford, South Parks Road, \\ Oxford OXI $3 Q U, U K$
}

(Received 25 October 1985 ; revised 4 February 1986)

\begin{abstract}
The Bacillus subtilis spoVE locus was isolated from a $\lambda$ clone bank and a $4.7 \mathrm{kbp}$ EcoRV fragment subcloned into the shuttle vector pHV33. The resulting plasmid complemented chromosomal spoVE mutations. Its structure was stable in recE4 strains, but plasmid and chromosomal rearrangements occurred in $\mathrm{rec}^{+}$strains. New spoVE mutations were obtained by mutagenesis of the plasmid; all the mutations tested mapped within three adjacent HindIII fragments of total length $1140 \mathrm{bp}$.
\end{abstract}

\section{INTRODUCTION}

Sporulation of Bacillus subtilis is a primitive system of cellular differentiation. At the start of the process, there is a single (vegetative) type of cell. This cell divides asymmetrically. The smaller cell that results, the forespore, is then gradually engulfed by the larger cell, the mother cell. These two cell types coexist for several hours, and both are necessary for the forespore to develop into the mature spore. At, or soon after, the completion of spore maturation, the mother cell lyses. Nearly 50 genetic loci thought to be specifically involved in spore formation have been identified by mutations (called spo mutations) that block sporulation but do not impair vegetative growth (Piggot \& Coote, 1976). Significant advances in our understanding of the regulation of spo locus expression have been made by studies of cloned spo loci (Losick \& Youngman, 1984; Piggot, 1985). These studies have concentrated on loci involved in the early part of sporulation. We are interested in analysing the control of gene expression during later stages, when the mother cell and forespore have been formed. To this end, we are interested in studying clones of loci whose expression is thought to be specific to each of the two cell types (Lencastre \& Piggot, 1979). The spoVA locus, thought to be expressed in the forespore, has been cloned (Piggot et al., 1984; Savva \& Mandelstam, 1984) and sequenced (Fort \& Errington, 1985). Here, we report the cloning of the spoVE locus, which is thought to be expressed in the mother cell (Lencastre \& Piggot, 1979).

\section{METHODS}

Strains. The B. subtilis 168 strains used are listed in Table 1. The Escherichia coli strains used were ED8767 (supE supF recA56 HsdS ${ }^{-} \mathrm{Met}^{-}$; Murray et al., 1977); DH1 (endAl hsdRI7 [Res-(K) $\left.\mathrm{Mod}^{+}(\mathrm{K})\right]$ supE44 thi-1 recAl gyrA96 relAI; Hanahan 1983); SL2034, a Dam ${ }^{-}$strain whose origin is obscure; and SL3617 (SL2034 transformed with pPP7, see text). Plasmids were maintained in DH1 or SL2034 when BclI was used, unless otherwise stated. The plasmid vectors used were pHV33 (Primrose \& Ehrlich, 1981) and pJAB1 (Sargent \& Bennett, 1985).

Identification of Charon 4A clones containing spoVE DNA. One thousand isolated plaques from the Charon 4A bank of Ferrari et al. (1981) were picked, suspended in $\lambda$ buffer and arranged in a three-dimensional matrix with

† Present address: Department of Microbiology and Immunology, Temple University School of Medicine, 3400 N. Broad Street, Philadelphia, PA 19140, USA.

¥ Present address: School of Biological Sciences, University of East Anglia, Norwich, UK. 
Table 1. B. subtilis strains

\begin{tabular}{|c|c|c|}
\hline Designation & Genotype/phenotype & Origin* \\
\hline GSY289 & pyrD1 trpC2 & C. Anagnostopoulos \\
\hline GSY908 & $\operatorname{argC4}$ hisAl recE4 & C. Anagnostopoulos \\
\hline SL14 & spoIIIE36 trpC2 & Laboratory stock \\
\hline SL54 & spoIIIE24 trpC2 & $\begin{array}{l}\text { DNA 24T (P. Schaeffer) } \times \text { SL10 (Lencastre \& Piggot, } \\
\text { 1979) } \rightarrow \text { Phe }^{+}\end{array}$ \\
\hline SL617 & spoIIG55 leuA8 tal-1 & Laboratory stock \\
\hline SL666 & spoVE85 metC3 tal-I & $\begin{array}{l}\text { DNA } 85 \text { (Hranueli et al., 1974) } \times \text { MB21 (Piggot \& } \\
\text { Taylor, 1977) } \rightarrow \text { Leu }^{+}\end{array}$ \\
\hline SL761 & spoOEI60 trpC2 & Laboratory stock \\
\hline SL931 & spoVD156 trpC2 rif-2 & Laboratory stock \\
\hline SL1022 & NonA $^{-}$NonB $^{-}\left(\mathrm{HsrM}^{-}\right)$leu-8 & Y12S (Saito et al., 1979) \\
\hline SL1093 & $\mathrm{NonA}^{-} \mathrm{HsrM}^{-}$arg-15 recE4 & DNA GSY908 $\times$SLl022 $\rightarrow \mathrm{Leu}^{+}$ \\
\hline SL1094 & NonA $^{-}$HsrM- leu-8 spoVE 153 & DNA W5 $\left(\right.$ Coote, 1972) $\times$ SL1022 $\rightarrow$ Arg $^{+}$ \\
\hline SL1095 & NonA $^{-} \mathrm{HsrM}^{-}$leu-8 spoVE85 & DNA SL666 $\times$SL1022 $\rightarrow$ Arg $^{+}$ \\
\hline SL1097 & NonA $^{-} \mathrm{HsrM}^{-}$spoVE85 recE4 & DNA GSY908 $\times$SL1095 $\rightarrow \mathrm{Leu}^{+}$ \\
\hline MB75 & metC3 lys-1 tal-1 & Laboratory stock \\
\hline MT1 & metC3 spoVEl tal-I & This paper \\
\hline MT2 & metC3 spoVE2 tal-I & This paper \\
\hline MT5 & metC3 spoVES tal-1 & This paper \\
\hline MT8 & metC3 spoVE8 tal-1 & This paper \\
\hline BR151 & metB 10 lys-3 trpC2 & R. S. Buxton \\
\hline
\end{tabular}

* Addresses: C. Anagnostopoulos, CNRS, Gif-Sur-Yvette, France; P. Schaeffer, Université Paris-sud, Orsay, France; R. S. Buxton, NIMR, Mill Hill, London, UK.

axes $x, y$ and $z$ numbered 0 to 9 . For each point on the $x$ axis, all the plaques in the other two dimensions were pooled (i.e. 100 clones). The procedure was repeated for the $y$ and $z$ axes, giving 30 pools (Monteiro et al., 1984). After amplification (DeWet et al., 1980), the phage DNA was prepared and screened for its ability to transform SL666 to Spo ${ }^{+}$. Eight of the $x$ pools, four of the $y$ pools, and three of the $z$ pools had substantial activity, indicating that abundant $s p o V E^{+}$clones were present. Using this information, ten positive clones were isolated; no attempt was made to isolate all the positive clones that might have been present.

In general, phage were handled as described by Monteiro et al. (1984).

Construction of pPP7. An EcoRV fragment of $4.7 \mathrm{kbp}$ from phage 732 had spoVE85+ transforming activity, and was separated from other fragments by agarose gel electrophoresis and purified by the method of Dretzen et al. (1981). It was ligated to pHV 33 that had been digested with EcoRV; pHV33 has a single EcoRV site within the determinant of tetracycline resistance. The ligated mixture was used to transform ED8767 to ampicillin resistance. Plasmid was prepared from the lawn of transformants obtained, and used to transform B. subtilis SL666 to chloramphenicol resistance. Six of 1052 such transformants were $\mathrm{Spo}^{+}$, and from each of these, plasmid DNA was prepared and used to transform E. coli SL2034 to ampicillin resistance. With five of the donors, the SL2034 transformants were tetracycline sensitive, suggesting insertion at the EcoRV site of pHV33; plasmid prepared from 12 such transformants had the size and transforming activity expected. One transformant, SL3617, with a plasmid designated pPP7, was used for further study.

Sporulation. Bacteria were induced to sporulate in liquid culture using Schaeffer's sporulation medium as modified by Leighton \& Doi (1971), except that cultures contained $5 \mu \mathrm{g}$ chloramphenicol $\mathrm{ml}^{-1}$. Viable counts were determined for cultures $18 \mathrm{~h}$ after the end of exponential growth by diluting cultures in Spizizen (1958) minimal salts containing $0.5 \%$ glucose and by plating them on nutrient agar. Spore counts at this time were determined by heating cultures to $85^{\circ} \mathrm{C}$ for $20 \mathrm{~min}$ and then diluting and plating.

Mutagenesis of plasmid pPP7. Plasmid DNA was treated with $o$-methylhydroxylamine as described by Bresler $e t$ al. (1983) except that a $0.75 \mathrm{M}$ solution was used. Mutants were tentatively identified as SpoV by the reddish-brown pigmentation of their colonies on nutrient agar. This was confirmed by examination with a phase contrast microscope, where SpoV mutants have a characteristic appearance (Piggot, 1978).

$M e d i a$. In general, $B$. subtilis strains were maintained on nutrient agar and $E$. coli strains maintained on $\mathrm{L}$ agar. Appropriate antibiotics were added, at the following concentrations, for strains harbouring plasmids: chloramphenicol $(\mathrm{Cm}), 5 \mu \mathrm{g} \mathrm{ml}^{-1}$; tetracycline, $20 \mu \mathrm{g} \mathrm{ml}^{-1}$; ampicillin, $25 \mu \mathrm{g} \mathrm{ml}^{-1}$. L agar (pH adjusted to 7.0) contained, per litre: Difco tryptone, $10 \mathrm{~g}$; Difco yeast extract, $5 \mathrm{~g} ; \mathrm{NaCl}, 10 \mathrm{~g}$; Difco agar, $16 \mathrm{~g}$. Nutrient agar consisted of Difco nutrient broth solidified by $1.6 \%(\mathrm{w} / \mathrm{v})$ Oxoid Bacteriological agar. Modified Schaeffer's sporulation medium ( $\mathrm{pH}$ adjusted to 7.0) contained, per litre: Difco nutrient broth, $16 \mathrm{~g} ; \mathrm{MgSO}_{4} .7 \mathrm{H}_{2} \mathrm{O}, 0.5 \mathrm{~g}$; $\mathrm{KCl}, 2 \mathrm{~g}$. This was freshly prepared, or re-steamed prior to use, as better sporulation was obtained by these 
procedures. $\mathrm{Ca}\left(\mathrm{NO}_{3}\right)_{2}$ (to $\left.10^{-3} \mathrm{M}\right), \mathrm{MnCl}_{2}\left(10^{-4} \mathrm{M}\right), \mathrm{FeSO}_{4}\left(10^{-6} \mathrm{M}\right)$ and giucose $(0 \cdot 1 \%$, w/v) were added before use (Leighton \& Doi, 1971).

Transformation. $\mathrm{Spo}^{+}$(chloroform-resistant) transformants were selected by the method of Hoch (1971). Transformation was done as described by Piggot et al. (1984).

Other methods. All other methods have been described previously (Piggot et al., 1984).

\section{RESULTS AND DISCUSSION}

Isolation of Charon $4 A$ clones containing spoVE ${ }^{+}$transforming activity

Ten spoVE $E^{+}$clones were identified and isolated from the Charon 4A bank of Ferrari et al. (1981). Each positive clone was reisolated twice from single plaques, and DNA was prepared from the phage. All gave the same restriction pattern on digestion with EcoRI, and so one isolate, 732, was used for further analysis. None of a series of strains with genetic markers located near to spoVE on the genetic map, namely SL931 spoVD156, SL617 spoIIG55, SL14 spoIIIE36, SL54 spoIIIE24, SL761 spoOE160,GSY289 pyrD1, gave wild-type recombinants with 732 DNA.

The restriction map of 732 DNA is shown in Fig. 1. The insert consisted of two EcoRI fragments of 2.8 and $10.5 \mathrm{kbp}$. These were identical in size to fragments of $B$. subtilis chromosomal DNA digested with EcoRI that hybridized to a probe derived from 732 DNA (pPP7, see below) on Southern (1979) blots, indicating that there had been no rearrangement on cloning.

The spoVE85+ transforming activity was located in the right end of the insert (in the sense of Fig. 1), as it was present in the $9.5 \mathrm{kbp} \mathrm{BamHI}$ fragment spanning this region. Neither of the EcoRI fragments of the insert were active in such a transformation, suggesting either that the spoVE85 mutation was near an EcoRI site or that the $2.8 \mathrm{kbp}$ fragment was too small to be active in transformation (data not shown).

\section{Construction of a plasmid that complements spoVE mutations}

It was established that a $4.7 \mathrm{kbp} E c o \mathrm{RV}$ fragment of 732 had spoVE85+ transforming activity. This fragment was isolated and subcloned into the single $E c o \mathrm{RV}$ site of pHV33 to produce pPP7, whose restriction map is shown in Fig. 2. The EcoRV fragments derived by restriction of pPP7 were identical in size to pHV33 cut with EcoRV and to the $4.7 \mathrm{kbp}$ fragment derived from 732; the $2.8 \mathrm{kbp} E c o \mathrm{RI}$ fragment from the insert in pPP7 was identical in size to the 732 fragment. This indicates that there was no rearrangement on subcloning. The map confirms and extends that of Yamada et al. (1983) for an independently isolated clone of spoVE. It should be noted that a portion of the cloned DNA in pPP7 was from the vector Charon 4A rather than B. subtilis; a complete map of EcoRV sites on 732 was not determined.

\section{Complementation of chromosomal spoVE mutations by pPP7}

B. subtilis $\mathrm{SL} 1097$ (spoVE85 recE4 $\mathrm{HsrM}^{-}$) was transformed to $\mathrm{Cm}^{\mathrm{R}}$ with pPP7 and with pHV33. All the pPP7 transformant clones were dark brown, and all those examined by phase contrast microscopy were $\mathrm{Spo}^{+}$. All pHV33 transformant clones were red-brown (characteristic of stage $\mathrm{V}$ mutants), and all those examined by phase contrast microscopy were blocked at stage $\mathrm{V}$ of sporulation (SpoV). Subculturing the pPP7 transformants in the absence of chloramphenicol led to the rapid segregation out of $\mathrm{Cm}^{\mathrm{s}} \mathrm{SpoV}$ bacteria. From this it was deduced that the cloned DNA on pPP7 functioned to complement the chromosomal spoVE85 mutation. Similar complementation was observed for the spoVE153 mutation, Transformation of SL1093

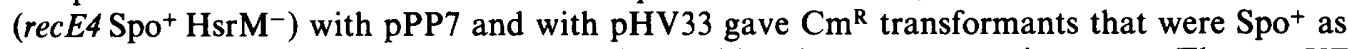
judged by observation of colony pigmentation and by phase-contrast microscopy. Thus spoVE did not show the inhibition of sporulation when present in multiple copies that has been noted for spoOF (Kawamura et al., 1981) and spoVG (Banner et al., 1983).

After the completion of the above experiments, Yamada et al. (1983) reported the cloning in the vector $\phi 105$ of an EcoRI fragment of about $2.6 \mathrm{kbp}$ that could complement the spoVE85 mutation. Their HindIII restriction map of this fragment agreed with ours. In contrast to our 


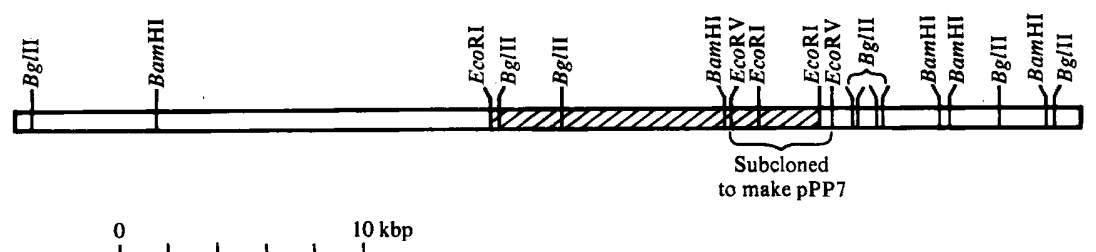

Fig. 1. Restriction map of phage 732. The insert of B. subtilis DNA within the Charon 4A arms is hatched; it is bounded by EcoRI sites. The map of EcoRV sites is incomplete; only those used to make pPP7 are shown.

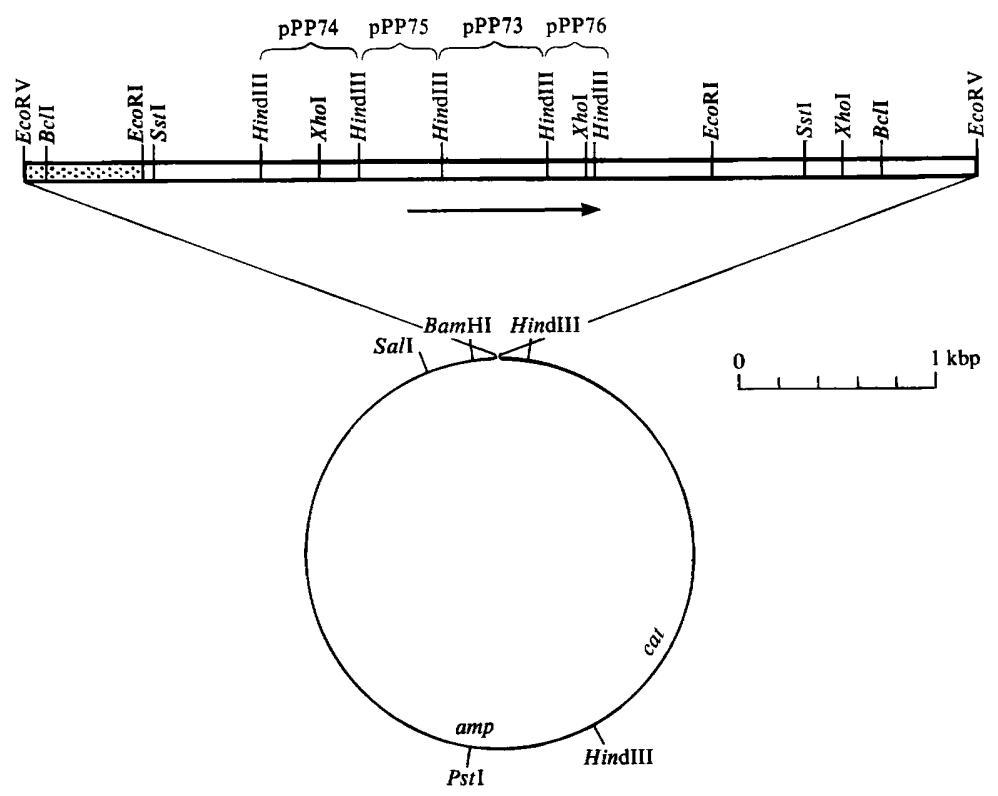

Fig. 2. Restriction map of pPP7. The insert from phage 732 is shown as a linear map, the vector, $\mathrm{pHV} 33$, as a circle. The part of the insert derived from Charon 4A is stippled. The insert is drawn in the opposite direction to that in Fig. 1 so that the direction of reading of the spoVE open reading frame, indicated by the arrow, is from left to right (see Bugaichuk \& Piggot, 1986). The map also shows the HindIII fragments subcloned in pJAB1 to create pPP73, pPP74, pPP75 and pPP76.

results, however, they reported that a subclone of the EcoRI fragment on the B. subtilis plasmid vector pUB110 inhibited sporulation of a recE4 $\mathrm{Spo}^{+}$strain. We therefore examined the effect of pPP7 on sporulation in liquid culture (Table 2). The sporulation of SL1097 (spoVE85/pPP7) was good, $28 \%$, although not as good as that of the strain with $s p o^{+}$chromosome (SL1093). Neither pPP7 nor pHV33 impaired the sporulation of the strain with a spo ${ }^{+}$chromosome, although with pPP7 the proportion of spores able to germinate and grow when chloramphenicol was added (presumably those harbouring plasmid) was greatly reduced (Table 2). This may indicate that pPP7 is readily lost even in the presence of chloramphenicol, and only when there is also a requirement for the spoVE $E^{+}$function of the plasmid do the majority of sporulating organisms retain the plasmid. These studies confirm the plate tests, showing that pPP7 complements chromosomal spoVE mutations efficiently and does not inhibit sporulation of a Spo ${ }^{+}$strain. The most probable explanation for this difference between our results and those of Yamada $e t$ al. (1983) is that they used pUB 110 as vector whilst we used pHV33. The difference may simply be a matter of copy number. pUB110 is reported to be present at about 40 copies per chromosome (Scheer-Abramowitz et al., 1981) and recombinant plasmids derived from pUB110 may have similar values. When pHV33 is vector, copy numbers are in the range 10 to 15 (Piggot et al., 
Table 2. Sporulation of strains harbouring plasmids

Bacteria were induced to sporulate in modified Schaeffer's medium containing $5 \mu \mathrm{g} \mathrm{Cm} \mathrm{ml}^{-1}$ (see Methods); $18 \mathrm{~h}$ after the end of exponential growth, a portion of each culture was diluted and plated on nutrient agar (NA), with and without $\mathrm{Cm}$. To determine the extent of sporulation, another portion was heated to $85^{\circ} \mathrm{C}$ for $20 \mathrm{~min}$ and then diluted and plated. Results shown are for duplicate cultures of each construct.

\begin{tabular}{|c|c|c|c|c|c|}
\hline \multirow{2}{*}{$\begin{array}{l}\text { Bacterial strain } \\
\text { and relevant } \\
\text { chromosomal } \\
\text { genotype }\end{array}$} & \multirow[b]{2}{*}{ Plasmid } & \multicolumn{2}{|c|}{$\begin{array}{l}10^{-7} \times \\
\text { Viable cells }\end{array}$} & \multicolumn{2}{|c|}{$\begin{array}{c}10^{-7} \times \\
\text { Heat resistance } \\
\text { spores }\end{array}$} \\
\hline & & NA & NA-Cm & NA & NA-Cm \\
\hline \multirow[t]{4}{*}{ SL1097 (spoVE85 recE4) } & pPP7 & $12 \cdot 0$ & $7 \cdot 9$ & $3 \cdot 3$ & 3.8 \\
\hline & pPP7 & $9 \cdot 5$ & $2 \cdot 7$ & 2.6 & 1.5 \\
\hline & pHV33 & $5 \cdot 2$ & $5 \cdot 9$ & $0^{*}$ & $0^{*}$ \\
\hline & pHV33 & 7.0 & $2 \cdot 1$ & $0^{*}$ & $0^{*}$ \\
\hline \multirow[t]{4}{*}{ SL1093 (spo ${ }^{+}$recE4) } & pPP7 & 13.6 & 1.0 & $11 \cdot 1$ & 0.8 \\
\hline & pPP7 & 14.5 & $4 \cdot 2$ & $13 \cdot 3$ & 1.25 \\
\hline & $\mathrm{pHV} 33$ & $22 \cdot 5$ & $15 \cdot 0$ & 18.7 & $16 \cdot 0$ \\
\hline & pHV33 & 15.9 & $23 \cdot 4$ & $16 \cdot 8$ & 13.8 \\
\hline
\end{tabular}

1985). Clearly spoVE does not show the very sharp sensitivity to copy number of $s p o O F$ where as few as five copies relative to the chromosome inhibit sporulation (Piggot et al., 1985).

\section{Plasmid stability}

The structure of plasmid pPP7 was stable in E. coli or in B. subtilis recE4 $\mathrm{HsrM}^{-}$strains such as SL1093 and SL1097 (although it showed segregational instability in B. subtilis). Thus with SL1097 as recipient and pPP7 as donor, $100 \%$ of $\mathrm{Cm}^{\mathrm{R}}$ transformant clones were dark brown. When pPP7 was transformed into Rec ${ }^{+}$SpoVE strains, however, it was structurally unstable. Thus $\mathrm{Cm}^{\mathrm{R}}$ transformants of SL666 $\left(\mathrm{HsrM}^{+}\right)$and SL1095 $\left(\mathrm{HsrM}^{-}\right)$had a mixture of colony morphologies with the majority being sectored for the pigment associated with sporulation; typically, $70 \%$ were sectored, $11 \%$ dark brown and $19 \%$ very lightly pigmented with no visible evidence of sectoring. On subculture in the presence, or absence, of chloramphenicol the sectored colonies have a mixture of dark brown, red-brown and poorly pigmented colonies; in the presence of chloramphenicol, sectored colonies were also obtained. Examination of the colonies with a phase-contrast microscope indicated that the dark-brown colonies were $\mathrm{Spo}^{+}$, the red-brown colonies SpoV, and the poorly pigmented colonies $\mathrm{Spo}^{-}$of an undetermined stage that was not $\mathrm{V}$. The colonies grown in the absence of chloramphenicol were $\mathrm{Cm}^{\mathrm{S}}$ and presumably had lost the plasmid; they were stable on subculture. This indicates that the chromosome was also subject to change in the presence of the plasmid; the $\mathrm{Spo}^{+}$segregants could be explained by homogenotization (Chak et al., 1982), but the Spo- (not stage V) $\mathrm{Cm}^{\mathrm{S}}$ segregants could not. The instability was not a function of the particular spoVE allele as it was also observed with SL1094 (spoVE153 rec ${ }^{+}$). The plasmid used in these experiments was prepared in E. coli. It contains sites for XhoI (Fig. 2), which is an isoschizomer of the endogenous $B$. subtilis 168 restriction enzyme $B s u \mathrm{M}$ (Jentsch, 1983). The instability was not caused by $B s u \mathrm{M}$, however, as it was exhibited by $h s r M$ strains that lack $B s u M$ activity. Rather, it appeared to be a consequence of $r e c E^{+}$activity. It was not investigated further.

\section{Isolation of new spoVE mutations}

The spoVE locus was defined by two mutations, spo- 85 and spo- 153 (previously called W5) (Piggot \& Coote, 1976). To obtain more chromosomal mutations in the region, pPP7 was mutagenized with hydroxylamine, and used to transform strain MB75 in the presence of an equimolar amount of $\phi 105 \mathrm{~d} l y s$ DNA (Jenkinson \& Mandelstam, 1983). The $\phi 105 \mathrm{~d} l y s$ DNA provided a selection for competent MB75, amongst which a proportion might be expected to have plasmid derived $B$. subtilis DNA integrated into the chromosome even though no selection 
Table 3. Localization of spoVE mutations within the cloned region

Strains with spoVE mutations were transformed with plasmids harbouring different portions of the spoVE region (see Fig. 2).

\begin{tabular}{|c|c|c|c|c|c|c|}
\hline \multirow[b]{3}{*}{ Recipient } & \multicolumn{6}{|c|}{ No. of $\mathrm{Spo}^{+}$transformants from $0.2 \mathrm{ml}$ transformed culture } \\
\hline & \multicolumn{6}{|c|}{ Donor: } \\
\hline & None & pPP73 & pPP74 & pPP75 & pPP76 & pPP7 \\
\hline SL666 (spoVE85) & 18 & 12 & 16 & 14 & 2240 & $>4000$ \\
\hline MT1 (spoVEI) & 0 & 4 & 1 & 692 & 5 & 3024 \\
\hline MT2 (spoVE2) & 0 & 660 & 6 & 1 & 3 & 1300 \\
\hline MT5 (spoVE5) & 3 & 852 & 2 & 7 & 2 & 2980 \\
\hline MT8 (spoVE8) & 0 & 0 & 5 & 784 & 1 & 2116 \\
\hline
\end{tabular}

was imposed for plasmid determinants (congression; Nester et al., 1963). Among $10000 \mathrm{Lys}^{+}$. transformants, $31 \mathrm{SpoV}$ mutants were identified in the initial screen; eight of these were found to be stable and transformable to $\mathrm{Spo}^{+}$with pPP7 DNA, suggesting that they were spoVE mutants. Four of the eight mutants were asporogenous. The asporogenous mutations were positioned within the cloned region by testing them with plasmids pPP73, 74, 75 and 76, which contained, respectively, the 560, 500, 360 and 220 bp HindIII fragments from pPP7 cloned in pJAB1 (Fig. 2). Plasmid pPP76 gave Spo ${ }^{+}$recombinants with SL666 (Table 3); pPP75 gave $\mathrm{Spo}^{+}$recombinants with MT1 and MT8; and pPP73 gave Spo ${ }^{+}$recombinants with $\mathrm{MT} 2$ and MT5. This indicates that the locus has a minimum size of $560 \mathrm{bp}$ and is likely to be significantly larger than that.

In an attempt to delimit the size of the transcriptional unit, and to see if there is a single unit, we used the integrational plasmid method (Piggot et al., 1984). This employs plasmids that cannot replicate in $B$. subtilis, and have a region of homology with the $B$. subtilis chromosome. When transformants are selected for a plasmid marker that is not in the region of homology, they arise by the plasmid integrating into the region of homology by a Campbell-like mechanism. When the region of homology is entirely within a transcriptional unit, then integration disrupts the transcriptional unit. The method depends upon the correctness of the assumption about the method of plasmid integration, and previous studies have shown it to be valid (Piggot et al., 1984). Unfortunately, it was found not to be valid for the spoVE region. Plasmids pPP73, 74 and 75 gave $\mathrm{Cm}^{\mathrm{R}}$ transformants of BR151 that were $\mathrm{Spo}^{+}$. However, analysis of DNA from the transformants showed that the plasmids had not integrated by a Campbell-like mechanism, so that no conclusions could be drawn above spoVE transcription from these experiments.

\section{REFERENCES}

Banner, C. D. B., Moran, C. P. \& Losick, R. (1983). Deletion analysis of a complex promoter for a developmentally regulated gene from Bacillus subtilis. Journal of Molecular Biology 168, 351-365.

Bresler, S. E., MachkovskiI, V. V., TAMM, S. E. \& Perumov, D. A. (1983). Mutagenesis of isolated plasmid with the help of $O$-methyl hydroxylamine. Doklady (Proceedings) of the Academy of Sciences of the U.S.S.R. (Biological Sciences) 269, 161-162.

Bugaichuk, U. D. \& Piggot, P. J. (1986). Nucleotide sequence of the Bacillus subtilis developmental gene spoVE. Journal of General Microbiology 132, 18831890.

Chak, K.-F., de Lencastre, H., LiU, H.-M. \& Piggot, P. J. (1982). Facile in vivo transfer of mutations between the Bacillus subtilis chromosome and a plasmid harbouring homologous DNA. Journal of General Microbiology 128, 2813-2816.

Coote, J. G. (1972). Sporulation in Bacillus subtilis. Genetic analysis of oligosporogenous mutants. Journal of General Microbiology 71, 17-27.

DeWet, J. R., Daniels, D. L., Schroeder, J. L., Williams, B. G., DENNiston-ThOMPSON, K., MOORE, D. D. \& BLATTNER, F. R. (198). Restriction maps for twenty-one Charon vector phages. Journal of Virology 33, 401-410.

Dretzen, G., Bellard, G. M., Sassone-Corsi, P. \& Chambon. P. (1981). A reliable method for the recovery of DNA fragments from agarose and acrylamide gels. Analytical Biochemistry 112, 295298.

Ferrari, E., Henner, D. J. \& Hoch, J. A. (1981). Isolation of Bacillus subtilis genes from a Charon 4A library. Journal of Bacteriology 146, 430-432.

ForT, P. M. \& ERrington, J. (1985). Nucleotide sequence and complementation analysis of a polycis- 
tronic sporulation operon, spoVA, in Bacillus subtilis. Journal of General Microbiology 131, 1091-1105.

Hanahan, D. (1983). Studies on transformation of Escherichia coli with plasmids. Journal of Molecular Biology 166, 557-580.

HoCH, J. A. (1971). Selection of cells transformed to prototrophy for sporulation markers. Journal of Bacteriology 105, 1200-1201.

Hranueli, D., Piggot, P. J. \& Mandelstam, J. (1974). Statistical estimate of the total number of operons specific for Bacillus subtilis sporulation. Journal of Bacteriology 119, 684-690.

Jenkinson, H. F. \& Mandelstam, J. (1983). Cloning of the Bacillus subtilis lys and spoIIIB genes in phage $\phi 105$. Journal of General Microbiology 129, 22292240.

JENTSCH, S. (1983). Restriction and modification in Bacillus subtilis: sequence specificities of restriction/ modification systems BsuM, BsuE, and BsuF. Journal of Bacteriology 156, 800-808.

Kawamura, F., Shimotsu, H., SaIto, H., Hirochika, H. \& KobaYASHI, Y. (1981). Cloning of spoO genes with bacteriophage and plasmid vectors in Bacillus subtilis. In Sporulation and Germination, pp. 109-113. Edited by H. S. Levinson, A. L. Sonenshein \& D. J. Tipper. Washington, DC: American Society for Microbiology.

LEIGHTON, T. J. \& DoI, R. H. (1971). The stability of messenger ribonucleic acid during sporulation in Bacillus subtilis. Journal of Biological Chemistry 246, 3189-3195.

LenCastre, H. DE \& Piggot, P. J. (1979). Identification of different sites of expression of spo loci by transformation of Bacillus subtilis. Journal of General Microbiology 114, 377-389.

Losick, R. \& Youngman, P. (1984). Endospore formation in Bacillus. In Microbial Development, pp. 63-88. Edited by R. Losick \& L. Shapiro. Cold Spring Harbor, NY: Cold Spring Harbor Laboratory.

Monteiro, M. J., Sargent, M. G. \& Piggot, P. J. (1984). Characterization of the replication terminus of the Bacillus subtilis chromosome. Journal of General Microbiology 130, 2403-2414.

Murray, N. E., Brammar, W. J. \& Murray, K. (1977). Lambdoid phages that simplify the recovery of in vitro recombinants. Molecular and General Genetics 150, 53-61.

Nester, E. W., Schafer, M. \& Lederberg, J. (1963). Gene linkage in DNA transfer: a cluster of genes concerned with aromatic biosynthesis in Bacillus subtilis. Genetics 48, 529-551.

Piggot, P. J. (1978). Organization of spo locus expression during sporulation of Bacillus subtilis: evidence for different loci being expressed in the mother cell and in the forespore. In Spores VIII, pp.
122-126. Edited by G. Chambliss \& J. C. Vary. Washington, DC: American Society for Microbiology.

Piggor , P. J. (1985). Sporulation of Bacillus subtilis. In The Molecular Biology of the Bacilli, vol. 2, pp. 73108. Edited by D. A. Dubnau. New York: Academic Press.

Piggor, P. J. \& Coote, J. G. (1976). Genetic aspects of bacterial endospore formation. Bacteriological Reviews 40, 908-962.

Piggot, P. J. \& TAYLoR, S. Y. (1977). New types of mutation affecting formation of alkaline phosphatase by Bacillus subtilis in sporulation conditions. Journal of General Microbiology 102, 69-80.

Piggot, P. J., Curtis, C. A. M. \& de Lencastre, H. (1984). Use of integrational plasmid vectors to demonstrate the polycistronic nature of a transcriptional unit (spoIIA) required for sporulation of Bacillus subtilis. Journal of General Microbiology 130, 2123-2136.

Piggot, P. J., Chapman, J. W. \& Curtis, C. A. M. (1985). Analysis of the control of spo gene expression in Bacillus subtilis. In The Molecular Biology of Microbial Differentiation, pp. 15-21. Edited by J. A. Hoch \& P. Setlow, Washington, DC: American Society for Microbiology.

Primrose, S. B. \& EhrLICH, S. D. (1981). Isolation of plasmid deletion mutants and study of their instability. Plasmid 6, 193-201.

SaIto, H., Shibata, T. \& ANDo, T. (1979). Mapping of genes determining nonpermissiveness and hostspecific restriction to bacteriophage in Bacillus subtilis Marburg. Molecular and General Genetics 170 , 117-122.

SARgent, M. G. \& Bennet, M. F. (1985). Amplification of a major membrane-bound DNA sequence of Bacillus subtilis. Journal of Bacteriology 161, 589-595.

Savva, D. \& MandelstaM, J. (1984). Cloning of the Bacillus subtilis spoIIA and spoVA genes in phage $\phi 105 \mathrm{DI}: 1 \mathrm{t} .-$ Journal of General Microbiology 130 , 2137-2145.

SCheER-Abramowitz, J., Gryczan, T. J. \& DUbNaU, D. (1981). Origin and mode of replication of plasmids pE194 and pUB110. Plasmid 6, 67-77.

SOUTHERN, E. (1979). Gel electrophoresis of restriction fragments. Methods in Enzymology 68, 152-176.

SPIZIZEN, J. (1958). Transformation of biochemically deficient strains of Bacillus subtilis by deoxyribonucleate. Proceedings of the National Academy of Sciences of the United States of America 44, 10721078.

Yamada, H., Anaguchi, H. \& Kobayashi, Y. (1983). Cloning of the sporulation gene spoVE in Bacillus subtilis. Journal of General and Applied Microbiology 29, 477-486. 